\title{
A poeta das "moradas da morte". Sobre a obra lírica de Nelly Sachs
}

\begin{abstract}
The article studies the German-speaking poetess Nelly Sachs, who received the Nobel-Prize for literature in 1966, together with Shmuel Agnon. In order to shed light upon the behind the decision of the jury, an overview on life and work of the author will be given and a number of poems will be analyzed.
\end{abstract}

Keywords: Nelly Sachs; Nobel-Prize; Holocaust-Poetry.

Zusammenfassung: Der Artikel behandelt die deutschsprachige Dichterin Nelly Sachs, die 1966 mit Shmuel Agnon den Nobelpreis für Literatur erhielt. In der Absicht, die Gründe für die Entscheidung der Jury zu beleuchten, wird ein Überblick über Leben und Werk der Autorin gegeben und einige ausgewählte Gedichte analysiert.

Stichwörter: Nelly Sachs; Nobelpreis; Holocaust-Dichtung.

Palavras-chave: Nelly Sachs; Prêmio Nobel; Poesia do Holocausto.

O autor é Professor de literatura alemã na Universidade de São Paulo. 


\section{@ 1. Um Prêmio Nobel para a literatura judaica}

O Prêmio Nobel de 1966 foi outorgado simultaneamente a dois autores cuja "produção literária recorda as vicissitudes de Israel e transmite sua mensagem aos povos do mundo", como afirmou Ingvar Andersson. ${ }^{1} \mathrm{O}$ galardão foi dividido entre o israelense Shmuel Yosef Agnon (1888-1970) por sua narrativa que "combina tradição e profecia, saga e sabedoria" e a cidadã sueca Nelly Sachs por escritos líricos e dramáticos que refletem o drama histórico pelo qual ela passara. Nas palavras de Andersson, Sachs foi honrada como "portadora de uma mensagem de consolo para todos que se desesperaram com o destino do homem". 2

Podemos deduzir desse discurso honorário que a intenção da Academia foi, naquele ano, distinguir dois escritores destacados da literatura judaica, sendo um deles expoente tanto da tradição ídiche da Europa Oriental ${ }^{3}$ como também da literatura hebraica do novo Estado de Israel e a outra representante dos judeus da Europa Central, que se consideraram integrados nas suas culturas nacionais até a ruptura civilizacional do Nazismo. É esta mesma ruptura, o genocídio, que é o tema central da obra de Nelly Sachs que, exilada na Suécia desde 1940, continuava escrevendo em alemão, embora sua língua materna se houvesse convertido em língua dos assassinos do seu povo.

40 anos após a premiação, Nelly Sachs é quase esquecida, ${ }^{4}$ enquanto um outro autor é considerado ao mesmo tempo poeta do Holocausto e

1 “Shmuel Yosef Agnon, Nelly Sachs - This year's literary Prize goes to you both with equal honour for a literary production which records Israel's vicissitudes in our time and passes on its message to the peoples of the world." http:// nobelprize.org/literature/laureates/1966/sachs-speech.html Traduções do autor.

2 "We honour you today as the bearer of a message of solace to all those who despair of the fate of man." Ibid.

3 Na verdade, a importância da obra de Agnon está na contribuição para o renascimento do hebraico como idioma de uma literatura moderna. Isto se reflete na decisão de dedicar o prêmio de 1978 ao último grande narrador em ídiche, Isaac Bashevis Singer.

4 As grandes histórias da literatura alemã dedicam, em geral, poucas linhas ou somente meias frases a Nelly Sachs e sua obra. O último volume do empreendi- 
também uma das maiores vozes líricas do século XX: Paul Celan, como Nelly Sachs, proveniente da burguesia assimilada judaica centro-européia, escrevendo em alemão e vivendo fora dos territórios onde a língua continuava sendo falada. Em 1966, os dois textos mais emblemáticos de Celan, "Todesfuge" e "Engführung" já estavam publicados ${ }^{5}$ e ele havia recebido dois prêmios importantes na Alemanha. Celan era, por conseguinte, reconhecido, famoso e, aos 46 anos, estava na faixa etária de outros premiados. ${ }^{6}$ Mas os responsáveis pela Academia preferiram condecorar Nelly Sachs em vez daquele poeta cuja estrela, nas décadas seguintes, involuntariamente, chegou a ofuscar a obra da sua amiga e "irmã mais velha". No que segue, gostaria de delinear vida e obra de Nelly Sachs e, particularmente, enfatizar os traços que, provavelmente, qualificaram seus poemas para o Prêmio.

\section{A vida e os começos literários de Nelly Sachs}

Nelly Sachs nasceu no dia 10 de dezembro 1891 como Leonie Sachs numa rica família de judeus assimilados em Berlim e passou uma infância protegi-

mento mais ambicioso na historiografia da literatura alemã (de Boor / Newald), trata em meia página a obra de Sachs e nestas linhas encontram-se as afirmações de que Sachs seja a "talvez mais nobre testemunha para a atualização do poema de vivência" (sic!) e que nos seus poemas, "a metafórica fica suspensa, as imagens valem literalmente". BARNER 1994: 87 ("Für die Aktualisierung des Erlebnisgedichts ist sie vielleicht die vornehmste Zeugin”; „Die Metaphorik ist ausgesetzt, die Bilder gelten wörtlich".)

No volume 10 da Sozialgeschichte der dentschen Literatur de Ludwig Fischer, Nelly Sachs recebe 10 linhas. (FIsCHER 1986: 252)

5 Os quatro livros que fundam a fama de Celan até hoje já haviam sido publicados entre 1952 e 1963.

6 Vários autores (Rudyard Kipling, Romain Rolland, Sinclair Lewis, Sigrid Undset, Pearl S. Buck, Albert Camus, Joseph Brodsky) receberam a distinção com menos de 50 anos. Na perspectiva de 1984, George Steiner considerou Celan "the profoundest, the most innovative lyric poet in western literature of our time" (Steiner 1984). Para o Nobel Prize Symposium do ano 1967, porém, Celan (como também: Moravia, Greene, Nabokov, Powys Grass e Borges) “ainda não estava no horizonte" (ESPMARK 1988: 204). 
@ da e, aparentemente, feliz, embora não tenhamos informações muito detalhadas sobre esta fase da sua vida. Existem, todavia, também algumas alusões vagas a aspectos trágicos desta primeira fase da filha única de Margarethe e William Sachs (cf. Dinesen 1994: 9-30; Fritsch-Vivié 1993: 19-36; OeLKer 1991: 208 ss.). Na biblioteca paterna, a jovem dedicou-se à leitura dos clássicos e românticos alemães e entusiasmou-se pela dança expressiva (“Ausdruckstanz") - queria até seguir a carreira de bailarina profissional. Um reflexo distante desta paixão juvenil pode ser reconhecido no valor místico que alguns poemas tardios atribuem à dança. ${ }^{7}$

Criada no âmago da cultura burguesa alemã do fim do século, a primeira experiência de leitura incisiva foi o livro Gösta Berling de Selma Lagerlöf, que dá início a uma correspondência da adolescente de 16 anos com a famosa escritora sueca e estimula os primeiros intentos de uma produção literária própria, publicados em forma de livro em 1921 (Legenden und Erääblungen). Mais tarde, estes contos e poemas românticos, criados longe dos debates árduos da Berlim vanguardista, não tinham mais valor para a autora. ${ }^{8}$ Mas foi o contato com Selma Lagerlöf que, décadas mais tarde, direcionou as negociações difíceis com a administração sueca, resultando em uma permissão para que Nelly Sachs e sua mãe pudessem imigrar para a Suécia; foi literalmente no último momento, porque o visto salvador chegou no mesmo dia que a ordem de apresentar-se para o transporte ao campo de trabalho forçado. A partir de 1940 até sua morte em 1970, ela viveu na Suécia.

Nelly Sachs queria que a informação biográfica sobre ela fosse buscada exclusivamente na sua obra. ${ }^{9}$ Sua vida, além da perseguição nazista, carece de grandes acontecimentos e mudanças, embora ela experimente tudo

7 P. ex. Chassidim Tanzen (Sachs 1988: 198), Tänzerin (ibid. 263), David (ibid. 274) SIE TANZT (ibid. 367). Sobre o aspecto da dança no poema TÄnZERIN ver INAUEN 2000: 222-224.

8 „Nelly Sachs menosprezou estes primeiros poemas como, coisas inocentes' e não os incluiu nos seus Poemas reunidos de 1961. Ela somente considerou sua lírica a partir de 1943 como válida." BAHR 1980: 40. ("Nelly Sachs hat diese frühen Gedichte als 'harmlose Sachen' abgetan und nicht in ihre Gesammelten Gedichte von 1961 aufgenommen. Sie hat nur ihre Lyrik seit 1943 als gültig betrachtet.”)

9 „Meus livros contêm tudo que alguém, talvez, queira saber sobre minha vida $[. .$.$] - eu, porém, quero que eu não seja considerada de nenhuma maneira". Briefe$ 
com uma grande sensibilidade. Aos 17 anos, ela se apaixonou por um homem não aceitável para a família - ele era divorciado - e este amor sem consumação quase a levou ao suicídio (cf. Fritsch-Vivié 1993: 37 ss.). ${ }^{10}$ No inverno de 1943/44, ficou sabendo que "uma pessoa muito próxima ... sofrera uma verdadeira morte de martírio" - tratava-se daquele homem que fora sujeito do seu amor em 1908; ele tinha sido assassinado num campo de concentração. (apud BAHR 1980: 47) Esta experiência foi o gatilho daquela fase de produção literária que causou a fama de Nelly Sachs. Ela afirmou mais tarde: "Eu escrevia como em chamas." E: "As imagens e metáforas são minhas feridas. A morte era meu professor. Eu escrevia para poder sobreviver." (apud BAHR 1980: 47 s.) $)^{11}$

Nelly Sachs nunca se casou. O pai morreu em 1930. Nelly e a mãe viveram em Berlim até a fuga em 1940 e em Estocolmo até o falecimento da Sra. Sachs em 1950. A partir desse momento, Nelly não tinha mais família, somente alguns poucos amigos e os "irmãos e irmãs mortos" aos quais dedicou o primeiro livro depois da guerra. A fama internacional começou somente nos anos sessenta, na última década de sua vida que já estava turvada por ataques psicóticos, de paranóia, que resultaram em anos de internação em hospitais psiquiátricos.

Nas suas próprias palavras, ela tinha que escrever "para poder respirar" (MülLER 1999: 439), sem a possibilidade de escrever ela "não teria sobrevivido" (GRAFE 2005: 6). Antes de receber atenção pública através dos grandes prêmios, sua obra foi reconhecida justamente por outros poetas, poetas que mediram a poesia com o supremo padrão de qualidade. Paul Celan procurou já nos anos 50 a amizade de Nelly Sachs e lhe dedicou vários de seus poemas.

der Nelly Sachs, apud Botte. („Meine Bücher enthalten alles, was vielleicht einer oder der andere wissen will über mein Leben [...] - ich aber will, daß man mich gänzlich ausschaltet - [...]")

10 Na biografia de Ruth Dinesen encontra-se uma "reconstrução" do perfil do "homem amado" por meio da interpretação dos sonetos amorosos e da peça "Merlin" da jovem poeta. Dinesen 1994: 48-79.

11 Estas afirmações reaparecem quase inalteradas muitas vezes, também numa carta a Gisela Dischner de 1966. Ver Grafe 2005: 5. 


\section{A obra}

Sua obra literária divide-se, portanto, em duas fases, separadas constitutivamente pela experiência do Nazismo. A primeira orientou-se nas formas e nos motivos de um século XIX que, a partir de 1933, estavam definitivamente obsoletos. Apesar de sua contemporaneidade com as grandes figuras da virada do século, como George, Hofmannsthal e Rilke, apesar de ter nascido e de viver na mesma época que os expressionistas alemães, ${ }^{12}$ ela não entrara em contato com os representantes da vanguarda e mantinha sua orientação pautada pela literatura do romantismo (cf. DisCHNER 1977: 310; Fritsche-Vivié 1994: 55). Uma “influência clássica” da modernidade, todavia, será importante para ela: a redescoberta de Hölderlin, que se deve ao círculo de Stefan George. (BAHR 1980: 36 s.) O verdadeiro encontro com a poesia do século XX aconteceu durante seu exílio na Suécia, de maneira indireta: nesta fase, Nelly Sachs traduz os poetas suecos da atualidade e os publica na Alemanha. Assim, ela se acostuma com as linguagens da vanguarda européia, como afirma Ehrhard Bahr, embora ela tenha negado que isto tivesse exercido uma influência em seu próprio estilo. (BAHR 1980: 50$)^{13}$

A partir de 1933, a perseguição dos judeus em Berlim provoca nela uma mudança notável. Se antes sua identidade estava inquestionavelmente arraigada na cultura e literatura alemãs, a identidade forçada instiga o estudo das tradições místicas do povo judeu: o hassidismo, a cabala, mas também autores cristãos da mesma corrente religiosa, como o dominicano Mestre Eckhart e o sapateiro silesiano Jacob Böhme. Nos anos 50, seus conhecimentos do judaismo místico aprofundaram-se por meio de um livro essencial da cabala medieval, o Sefer ha-zohar, Livro do Brilho, na tradução alemã de Gershom Scholem, autor do qual ela leu também o estudo acadêmico sobre $A$ mistica judaica nas suas correntes centrais. Esta ocupação com as

12 Ela nasce no mesmo ano que Johannes Becher, Ferdinand Bruckner e Yvan Goll.

13 Na carta a Gisela Dischner (nota 11), Nelly Sachs desmentiu qualquer influência literária; eram somente "as vivências terríveis" que eram "sua mestre", afirmação colocada em dúvida por G. Discher. Ver GrafE 2005: 6. 
várias expressões da fé mística acompanhará Nelly Sachs até sua morte. Não é uma crença estabelecida por instituições, revelações ou uma comunidade de fiéis, mas uma busca desesperada de um deus escondido, sempre ameaçada e, em grande parte, empreendida através da própria literatura que Nelly Sachs escreve durante seu exílio, na sua nova pátria. Trata-se de narrativas, peças dramáticas e de poesia lírica que motivaram a sua fama e que lhe trouxeram o Prêmio Nobel em 1966, quatro anos antes da sua morte.

As primeiras publicações no período pós-guerra realizaram-se fora da Alemanha Federal: In den Wohnungen des Todes (Nas moradas da morte; Berlim oriental, Aufbau Verlag 1947), Sternverdunkelung (Eclipse estelar, Amsterdam, Berman Fischer 1949) e Eli. Ein Mysterienspiel vom Leiden Israels (Eli. Mistério Dramático das Tribulações de Israel; ${ }^{14}$ Malmö, Forsell 1951). Seguem vários livros de poemas; os mais importantes são Und niemand weiß weiter ( $E$ ninguém sabe seguir, Hamburg, Ellermann 1957), Flucht und Verwandlung (Fuga e metamorfose; Stuttgart, DVA 1959), a coletânea Fahrt ins Staublose (Viagem para o sem pó; Frankfurt a. M., Suhrkamp 1961), Glühende Rätsel (Enigmas ardentes; Frankfurt a. M., Insel 1964) e Späte Gedichte (Últimos poemas; Frankfurt a. M., Suhrkamp 1965).

Os poemas dos quarenta caracterizam-se pela temática comum, o holocausto. São organizados, geralmente, em ciclos (Gebete für den toten Bräutigam, Grabschriften in die Luft geschrieben, Chöre nach Mitternacht; Preces para o noivo morto, Epitáfios escritos no ar, Corais após meia-noite); evocam as vozes dos extinguidos, falam das coisas que sobraram ou entoam o lamento da sobrevivente (um exemplo será analisado no que segue). Oscilam entre a denominação concreta do extermínio e uma linguagem figurativa inusitada: metáforas e comparações que "combinam elementos díspares" e, portanto, reconfiguram o significado das palavras abusadas pelo regime totalitário (DisCHNER 1977: 335).

No seu percurso, a poesia de Nelly Sachs vai intensificar o emprego de imagens enigmáticas, aproximando-se da metáfora absoluta, a metáfora que recebe seu significado completamente pelo co-texto do poema, como

14 A tradução do título se deve a Samuel Usque; ver HoERSTER. 
๑ O "leite negro" da "Todesfuge" de Paul Celan (cf. Dischner 1977: 345 s.). $\overline{\overline{\bar{\sigma}}}$ A escuridão, produzida por recursos poéticos como este, é, por um lado, I uma característica geral da poesia moderna. No caso de Sachs e Celan, no Z entanto, a escuridão não é o mero resultado de um jogo artístico ou até

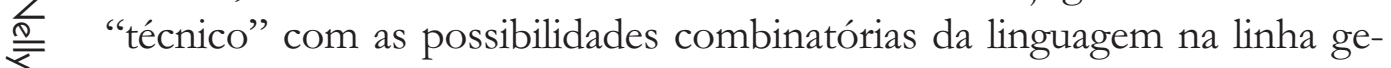
थn nealógica de Mallarmé e Valéry. ${ }^{15}$ O hermetismo de Nelly Sachs tampouco 气े invoca, de forma direta, as eternas fórmulas paradoxais do misticismo. A metáfora absoluta no contexto da poesia de Sachs e Celan é, em primeiro lugar, a expressão indireta daquilo que, na sua dimensão histórica e humana, não pode ser imaginado e, menos ainda, ser verbalizado com as ferramentas da linguagem instrumental e referencial.

A intertextualidade bíblica e mística, que na poesia lírica constitui um eixo entre outros, está muito mais presente nos poemas cênicos. Eli, escrito durante três noites do inverno de 1943, "em pobreza, doença e desespero completo" (apud BRAUNECK 2000), tematiza a morte de um jovem pastor que foi assassinado por um soldado alemão. $\mathrm{Na}$ ficção, os judeus sobreviventes refundam, depois da catástrofe, sua vila na Polônia. A única casa poupada é a do sapateiro Michael, que sente a vocação de achar o assassino de Eli. As cenas da reconstrução constrastam com o horror das memórias. Quando Michael, finalmente, encontra o assassino, este decompõe-se em pó pelo brilho divino na frente de Michael, figura que simboliza um dos 36 justos da lenda hassídica. A peça foi encendada no teatro e para o rádio e posta em música. A visão da nêmesis punitiva que se revela no simbolismo da trama e a polaridade entre vítimas e algozes é representativa para o imaginário da autora e sua necessidade de transcender o fato bruto da destruição.

15 Cf. Enzensberger (1977: 356) „Bei Nelly Sachs ist sie [die Schwierigkeit] niemals technischer Herkunft; sie hat weder Verfremdung noch Kalkül im Sinn, ihre Poesie ist weder Codeschrift noch Vexierbild; wir haben es hier mit Rätseln zu tun, die in ihrer Lösung nicht aufgehen, sondern einen Rest behalten - und auf diesen Rest kommt es an.” („Em N.S., a dificuldade nunca é de origem técnica; ela não é motivada por um distanciamento ou um cálculo, sua poesia não é nem código nem imagem ambígua; enfrentamos aqui enigmas que não se esgotam na sua solução, mas que mantêm um resto - e é este resto que importa.") 


\section{As "moradas da morte"}

Aos 56 anos de idade, publica-se In den Wohnungen des Todes (Nas moradas da morte), seu primeiro livro de poemas. Os textos do ciclo falam inconfundivelmente do extermínio industrial, começando com o poema

O DIE SCHORNSTEINE

Auf den sinnreich erdachten Wohnungen des Todes,

Als Israels Leib zog aufgelöst in Rauch

Durch die Luft -

Als Essenkehrer ihn ein Stern empfing

Der schwarz wurde

Oder war es ein Sonnenstrahl?

O die Schornsteine

Freiheitswege für Jeremias und Hiobs Staub -

Wer erdachte euch und baute Stein auf Stein

Den Weg für Flüchtlinge aus Rauch?

O die Wohnungen des Todes,

Einladend hergerichtet

Für den Wirt des Hauses, der sonst Gast war -

$\mathrm{O}$ ihr Finger,

Die Eingangsschwelle legend

Wie ein Messer zwischen Leben und Tod -

O ihr Schornsteine,

O ihr Finger,

Und Israels Leib im Rauch durch die Luft!

(Sachs 1988: 8)
Ó AS CHAMINÉS

Sobre as moradas da morte, pensadas sensatamente

Quando o corpo de Israel passou, solvido em fumaça, Pelo ar -

Como limpa-chaminés lhe recebeu uma estrela

que se tornou negra

Ou foi um raio de sol?

Ó as chaminés

Caminhos de liberdade para o pó de Jeremias e Jó

Quem vos pensou e vos construiu pedra sobre pedra

$\mathrm{O}$ caminho para refugiados de fumaça?

Ó as moradas da morte,

Arranjadas convidativamente

Para o dono da casa, outrora hóspede -

Ó vocês dedos

Colocando o limiar da entrada

Entre vida e morte como uma faca -

Ó vocês chaminés

Ó vocês dedos

E o corpo de Israel na fumaça pelo ar! ${ }^{16}$

No poema inicial do ciclo já se percebem algumas características da lírica de Nelly Sachs. Por um lado, evoca e lamenta indubitavelmente o fato histórico do genocídio: a extinção de milhões de seres humanos, sua transformação em nada. Por outro lado, trata de relacionar este fato a um espaço cósmico que transcende a simples destruição física. A fumaça negra alcança uma esfera de luz (estrela / raio de sol), mesmo que esta não consiga manter sua capacidade iluminante contra a força ofuscadora da fumaça. E a cremação não é apresentada como ato final da aniquilação, senão como saída, fuga: as chaminés são os caminhos de liberdade para aqueles que sofreram nas moradas da morte.

16 Trad. do autor. As traduções portuguesas de Paulo Quintela, comentados no artigo de Hörster, não estavam ao meu alcance. 
$\mathrm{Na}$ dimensão sobrenatural, o simbolismo poético distingue entre as esferas da vida (luz, estrela, sol) e da morte (escuridão, fumaça, pedra, pó) que, no imaginário místico, encontrariam-se numa dialética eterna (cf. DischNer 1977); mas esta dialética está ameaçada pelo extremo dos acontecimentos históricos: estrela e sol são ofuscados pela fumaça saindo dos crematórios. E embora o "corpo de Israel" fuja à "morada da morte", não chega a ser recolhido num estado "de salvação", como implicaria a intenção mística.

As sinédoques remetem diretamente à morte nos campos de extermínio como "chaminés" e "fumaça", a metáfora "moradas da morte" e as comparações meio obscuras como "limiar como uma faca entre vida e morte". As "moradas" referem-se de forma explícita às câmaras de gás, mas a expressão do "limiar" que compara-se a uma "faca" dissolve a imaginação concreta por meio da sua estranheza. De modo semelhante, a imagem grotesca do "limpa-chaminés", resultante da cena do corpo queimado que passa pelo tubo, é uma personificação que não "funciona" mais como imaginação visual. O limiar como faca tampouco "funciona" visualmente, mas abala os quadros da nossa experiência de casas, portas e limiares, introduzindo um elemento altamente perturbador no cenário habitual.

O vocabulário simples provém das esferas fundamentais da vida humana e do cosmos: corpo, dedo, faca, morada, limiar, caminho, estrela, ar, fumaca, vida, morte. Os nomes Jó, Jeremias, Israel identificam os exterminados com os ancestrais bíblicos e vinculam os indivíduos modernos à tradição milenária do povo judeu.

É evidente que o poema, de alguma maneira, é expressão da dor, mas a dor de quem? Onde se manifesta? A interjeição "Ó” pode expressar páthos e sofrimento, mas aqui representa mais a perplexidade, a falta de palavras para descrever as chaminés e aquilo que está e o que acontece embaixo delas (cf. BACH 1989: 368). A interjeição é convertida, no percurso dos versos, num gesto de invocação, proveniente da linguagem religiosa, da prece, da litania, do salmo, e desta esfera sagrada também empresta a força mágica das repetições. Mas o gesto da invocação não é seguido por uma atribuição. De que se acusam as chaminés? Os dedos? O elemento faltante - marcado também pelos travessões que terminam vários versos - manifesta o gesto da voz sufocada que fica calada frente ao tamanho do aconte- 
cimento - um recurso literário observado amplamente na literatura do holocausto e na poesia moderna em geral. ${ }^{17}$

As frases não falam da dor, não acusam ninguém, não lamentam a morte - somente descrevem, denominam os fatos, colocam perguntas "retóricas" e constatam: "o corpo de Israel na fumaça pelo ar": o povo é dissolvido em nada. A imagem da "morada da morte" evoca algo da absurda 'normalidade' destas fábricas, construídas para que produzissem a extinção de vidas humanas. O processo organizado por meio da especialização é enfocado nas perguntas sobre o planejamento e a construção destas "moradas", dos "dedos" que colocaram o "limiar entre vida e morte". Sem denúncia direta, alude-se àquela sociedade civilizada e 'humana' que foi responsável pelo massacre. Enquanto a seqüência inicial de frases coloca os acontecimentos no pretérito e na terceira pessoa, a última estrofe, repetindo os elementos centrais do poema, com a falta do verbo finito e com a invocação direta de "chaminés" e "dedos", converte todo o processo em algo extremamente presente e aflitivo.

Os "dedos" anônimos, por outro lado, focalizam o aspecto corpóreo dos assassinos. São os dedos vulneráveis, compartilhados com os outros seres humanos, que cometem a agressão. Quem executa o mal aqui, não difere substancialmente das suas vítimas, e tanto mais difícil é compreender como podiam cometê-lo. As mãos humanas podem ser imaginadas, não os rostos individuais.

Nota-se também a linguagem particular em expressões como as moradas "pensadas sensatamente" e "e arranjadas atraentemente / para o dono da casa, outrora hóspede". São formulações arcaizantes que remetem diretamente a Hölderlin que, na sua elegia "O passeio ao campo" (Der Gang aufs Land), fala da casa que o "sensato anfitrião construiu para seus hóspedes”, esperança pela civilização bem sucedida que, aliás, já para Hölderlin está ameaçada por uma "época de chumbo" (die bleierne Zeit). ${ }^{18}$ No con-

\footnotetext{
17 Cf. entre outros: KorTE 1999. A tendência de "emudecer" do poema moderno, contra a qual este se mantém, é uma observação central do discurso teórico de Paul Celan (Celan 1999: 8)

18 Nämlich droben zu weihn bei guter Rede den Boden,
}

Wo den Gästen das Haus baut der verständige Wirt; 
texto do poema, não se trata de empréstimos epigonais, mas de uma citação que expõe a inversão do projeto da humanidade, realizada pelos nazistas que, por sua vez, declararam seu "Terceiro Império" o supremo cumprimento das intenções daquele poeta patriótico. Além disso, a referência a Hölderlin vincula o poema às duas tradições centrais que confluem na obra tensa e ambiciosa do Suábio: Atenas e Jerusalém, a antiguidade grega e a religião judaico-cristã. No tom desta herança do idealismo alemão, a poeta enfatiza o elemento judaico: Israel como personificação do povo inteiro, Jeremias e Jó como exemplos do sofrimento e do martírio que este povo suportou na sua história, sem renunciar à sua fé. ${ }^{19}$

\section{Críticas à poesia de Nelly Sachs}

O anseio por uma reconciliação da morte - mesmo da morte massiva, industrializada - com um sentido, um princípio místico expressa-se já na divisa que precede o poema, uma citação de Jó: "Und wenn diese meine Haut zerschlagen sein wird, so werde ich ohne mein Fleisch Gott schauen." Em português isto significa: "E quando minha pele for destroçada, eu, sem minha carne, verei Deus." ${ }^{20}$ Implica a idéia de uma reunião da alma com o

Daß sie kosten und schaun das Schönste, die Fülle des Landes,

Daß, wie das Herz es wünscht, offen, dem Geiste gemäß

Mahl und Tanz und Gesang und Stuttgarts Freude gekrönt sei,

Deshalb wollen wir heut wünschend den Hügel hinauf.

Hölderlin: „Der Gang aufs Land.” In: Kleine Stuttgarter Ausgabe. Ed. Fr. Beissner. Stuttgart: Cotta 1946. Bd. 2, 88-89.

19 Cf. também BACH (1989: 366) que afirma: "Grundsätzlich muß man davon ausgehen, daß die Gedichte von Nelly Sachs, und vor allem gerade die der „Sternverdunkelung”, eher an Hölderlin und Novalis orientiert sind, als an der hebräischen Poesie, mögen die inhaltlichen Bezüge zum Alten Testament auch noch so auf der Hand liegen."

20 O trecho citado por Nelly Sachs se assemelha à versão da Bíblia luterana do início do século passado: "Und nachdem diese meine Haut zerschlagen ist, werde ich ohne mein Fleisch Gott sehen." (Die Bibel oder die ganze Heilige Schrift des Alten und Neuen Testaments. Nach der deutschen Übersetzung D. Martin Luthers. Neu durchgesehen nach dem vom Deutschen Evangelischen Kirchenausschuß genehmigten Text. Berlin s. a.) 
divino após a morte. Tal idéia necessariamente reduz o impacto do terror e coordena, mesmo tentativamente, o crime nazista com uma razão superior, subjacente a toda a criação e história.

É este elemento - do poema em particular e da obra de Nelly Sachs em geral - que levantou dúvidas por parte de uma certa fração da crítica e estas dúvidas, com o passar dos anos, permaneceram e aumentaram. O próprio texto do poema reflete-se nos "caminhos de liberdade". Trata-se, evidentemente, de uma idéia consolatória, tópica, que a morte seja uma liberação dos tormentos terrestres, mesmo que a metáfora aqui não se vincule a uma concepção de ressurreição ou vida eterna de índole cristã. Mesmo assim, a associação segundo a qual as chaminés dos crematórios seriam o meio de libertação para os judeus parece grotesca - como se não tivessem sido exatamente os mesmos nazistas que causaram tanto a morte dos judeus como também as torturas das quais a morte deve libertá-los. Fica mais patente ainda quando se responde à pergunta retórica "Quem vos construiu e colocou pedra sobre pedra": evidentemente foram os alemães nazistas e seus cúmplices que construíram as chaminés, mas por outro lado - não foi Deus que construiu os caminhos de liberdade para Israel? Os nazistas eram então somente uma ferramenta na mão de Deus? E, se o caminho da liberdade foi providenciado por Deus - os campos de concentração também o foram? Aí estamos bem no centro da problemática de uma fé após Auschwitz. O poema de Nelly Sachs não esconde esta problemática, mas tampouco pode solucioná-la.

O impulso místico, o desejo de reconciliação de Nelly Sachs, aparentemente, hesita frente à possibilidade de que esta morte de milhões de homens, mulheres, crianças, pudesse realmente carecer de qualquer sentido. $\mathrm{Na}$ medida em que ela amplia este destino para uma condição existencial do povo de Israel e, num segundo passo, da humanidade, o Holocausto

O verso corresponde a Jó 19, 26, mas o texto hebraico não é claro e, por conseguinte, a Bíblia portuguesa apresenta uma tradução diferente, de acordo com a interpretatio christiana do verso anterior: " 25 Porque eu sei que meu Redentor vive, / que no último dia ressurgirei da terra, / ${ }^{26}$ serei novamente revestido da minha pele, / e na minha própria carne verei Deus." Bíblia sagrada. Tradução da Vulgata pelo Pe. Matos Soares. São Paulo: Ed. Paulinas 1989. 
๑ como crime histórico e inaudito integra-se em um contínuo de sofrimento da espécie humana. A partir de um ponto de vista não religioso que, necessariamente, deve insistir no absurdo absoluto do Holocausto, esta idéia aliviadora para os responsáveis fica obsoleta, quase obscena. A questão da religiosidade era, conseqüentemente, o ponto polêmico discutido por Nelly Sachs e Paul Celan, quando eles se encontraram em Zurique, depois de anos de correspondência por cartas e poemas. No poema "Zürich, zum Storchen", Paul Celan tematiza o encontro, a conversação e o dissenso (Celan 1996: 14 s.). ${ }^{21}$

Durante os anos cinqüenta e sessenta, esta interpretação "reconciliadora" conferiu uma certa absolvição à comunidade dos responsáveis, como observou KORTE (1999: 27): O passado criminoso dos alemães “encontrava-se incorporado e neutralizado dentro de uma metafísica da história humana de vítimas e perpetradores, com perspectiva de reconciliação e entendimento". ${ }^{22}$ O público alemão queria, nas duas décadas que se seguiram ao fim da $2^{\text {a }}$ Guerra, em primeiro lugar esquecer seu passado horroroso, e, quando a memória se impôs de maneira imperiosa, buscava formas que aliviavam o peso da culpa. Houve, portanto, uma certa recepção alemã que privilegiou aqueles elementos na poesia de Sachs que transpõem o holocausto para uma figura do sofrimento humano de todos os tempos. O que foi pronunciado para aliviar uma vítima da sua culpa de sobrevivência serviu agora aos próprios responsáveis pelo genocídio e seus compatriotas para festejar a reconciliação. Nos discursos públicos, Nelly Sachs foi declarada a "poeta do povo judeu" - em vez de recordar e revogar sua "excomunhão" da sociedade e cultura alemãs. Enquanto os poemas, de fato, realizam atos de rememoração do extermínio, esta re-

21 Na obra de Nelly Sachs não existe um texto que responde diretamente ao encontro da mesma maneira. No encontro, ela presenteou o manuscrito do poema "Du in der Nacht" a Celan. O poema "Mund saugend am Tod" foi publicado junto com "Zürich, zum Storchen" na Neue Zürcher Zeitung. Os dois podem ser interpretados em vista ao amigo, mas a referência permanece hipotética. Cf. Celan / Sachs 40 ss. (Ver o artigo de Juliana Perez sobre Paul Celan neste Dossiê.)

22 „Die Vergangenheit war in der Metaphysik der Täter- und Opfergeschichte der Menschheit mit Aussicht auf Versöhnung und Verständigung aufgehoben.” 
cepção percebe a sua obra como uma restituição cultural dos "afogados" que equivale quase às compensações econômicas - denominadas, com certa infâmia, de "Wiedergutmachung". Neste raciocínio, o "Coro dos mortos" e outros poemas podiam contar como pedra sepulcral enterrando qualquer lembrança viva. ${ }^{23}$

Muitos dos textos de Nelly Sachs possuem esta ambigüidade, como notou-se no primeiro poema com sua alusão à "liberdade" dos mortos. Por outro lado, o ciclo contém textos que não permitem uma leitura reconciliadora e somente mostram o sofrimento dos extintos. Gostaria de apresentar, neste contexto, pelo menos mais um poema, que deve falar por si mesmo.

EIN TOTES KIND SPRICHT

Die MUTTER hielt mich an der Hand.

Dann hob Jemand das Abschiedsmesser:

Die Mutter löste ihre Hand aus der meinen,

Damit es mich nicht träfe.

Sie aber berührte noch einmal leise meine Hüfte -

Und da blutete ihre Hand -

Von da ab schnitt mir das Abschiedsmesser

Den Bissen in der Kehle entzwei -

Es fuhr in der Morgendämmerung mit der Sonne hervor

Und begann, sich in meinen Augen zu schärfen -

In meinem Ohr schliffen sich Winde und Wasser,

Und jede Trostesstimme stach in mein Herz -

Als man mich zum Tode führte,

Fühlte ich im letzten Augenblick noch

Das Herausziehen des großen Abschiedsmessers.

(Sachs 1988: 13)
UMA CRIANÇA MORTA FALA

A MÃE me segurava pela mão.

Depois Alguém levantou a faca de despedida:

A mãe soltou sua mão da minha

Para que a faca não me apanhasse.

Ela, porém, tocou outra vez levemente minha anca E então sua mão sangrava -

Desde então a faca de despedida me cortava

$O$ bocado na garganta em dois -

Surgiu na alvorada com o sol

E começou a afiar-se nos meus olhos -

$\mathrm{Na}$ minha orelha se amolaram os ventos e as águas,

E cada voz de consolo me perfurou o coração -

Quando me levaram para a morte,

Senti ainda no último momento

Como se tirassem a grande faca de despedida.

Será difícil qualificar este poema como um epitáfio oportuno para tranqüilizar a consciência dos culpados, mesmo que não insista na instância que atua e mesmo que não descreva nenhuma brutalidade real. Em vez disso, a vOz da poeta coloca-se completamente na perspectiva da vítima infantil e manifesta a separação da sua mãe de forma metafórica. A "grande faca de despedida", no entanto, está onipresente, contamina tudo que acontece,

23 Cf. SPARr 1998. 
mais forte, esteticamente, que uma atrocidade detalhada. Foi observado que a cena evoca, de forma inversa, o sacrifício de Isaac. ${ }^{24}$

Mas existe uma crítica ainda mais fundamental, formulada por Adorno e retomada várias vezes pelo próprio autor, como também foi citada ad nauseam em contextos de poesia e Holocausto. Nas palavras de Adorno, "é barbárie escrever um poema após Auschwitz". (Adorno GS 10, 1: 30) Em resposta à forte crítica contra seu veredicto, Adorno assevera sua tese na Dialética negativa, por um lado, reduzindo a poesia ao nível do "grito do torturado" (GS 6: 355) e insistindo, por outro lado, que após Auschwitz "toda cultura é lixo" (GS 6: 359). Contudo, seria completamente equivocado deduzir deste veredicto que Adorno queria proibir a atividade cultural em favor de uma sociedade tecnocrática que continuasse sem esta dimensão de reflexão - pelo contrário. O filósofo queria enfatizar o que o fato de Auschwitz ter acontecido em princípio tornou impossível qualquer atividade exercida "normalmente" - inclusive a vida. Não obstante, ele deu razão à intervenção de Hans Magnus Enzensberger, que "a própria poesia deveria resistir a este veredicto, na medida em que ela assumisse uma forma que a salvasse do puro cinismo" (GS 11: 422). "A abundância do sofrimento não tolera o esque-cimento", diz Adorno, e "este sofrimento requer a continuidade de uma arte, que proíbe o sofrimento" (GS 11: 422). ${ }^{25}$

$\mathrm{Na}$ argumentação de Adorno (como na sua obra inteira), não se encontra uma menção direta a Nelly Sachs. Mas a intervenção de Enzensberger foi feita exatamente num ensaio sobre a poeta, publicado em 1959. No texto, Enzensberger afirma a necessidade de refutar a frase de Adorno, "se quisermos continuar vivendo". (ENZENSBERGER 1995: 72) São poucos, se-

24 Ver Peterson 202.

25 „Aber wahr bleibt auch Enzensbergers Entgegnung, die Dichtung müsse eben diesem Verdikt standhalten, so also sein, daß sie nicht durch ihre bloße Existenz nach Auschwitz dem Zynismus sich überantworte. Ihre eigene Situation ist paradox, nicht erst, wie man zu ihr sich verhält. Das Übermaß an realem Leiden duldet kein Vergessen; Pascals theologisches Wort »On ne doit plus dormir« ist zu säkularisieren. Aber jenes Leiden, nach Hegels Wort das Bewußtsein von Nöten, erheischt auch die Fortdauer von Kunst, die es verbietet; kaum wo anders findet das Leiden noch seine eigene Stimme, den Trost, der es nicht sogleich verriete." (AdORNo GS 11: 422) 
gundo Enzensberger, que possuem esta capacidade e Nelly Sachs faz parte deles (ibid.). Ele enfatizou, aliás, que o direito de perdoar e reconciliar cabe somente às vítimas e que a única postura de "nós, os outros" seria denunciar os responsáveis - com esta ressalva, porém, ele não consegue evitar a tendência da política comemorativa dos anos 60, que se apoderou da obra de Nelly Sachs para seus fins particulares.

\section{A decisão da Academia}

Chegando ao fim, cabe, mais uma vez, a pergunta com respeito ao Prêmio Nobel: Porque Nelly Sachs e não Paul Celan - uma vez que o último está, hoje em dia, muito mais presente no debate crítico?

A relação entre Paul Celan e Nelly Sachs estava menos intensa desde o encontro em Zurique, também porque a poeta, de volta da sua visita tímida à Alemanha, sofreu de ataques paranóicos e ficou hospitalizada durante três anos. Paul Celan, por sua vez, foi internado várias vezes desde 1962 (Emmerich 1999: 125, 129, 137). Quando ela recebeu a notícia do Prêmio, no dia 20 de outubro, o casal Celan telegrafou imediatamente suas felicitações (CELAN / SACHS 90). Convidado para a festa de entrega - que coincidiu com o $75^{\circ}$ aniversário da poeta - Celan desistiu por causa das obrigações na École Normale, referindo-se às "férias lamentavelmente muito extensas" que ele tirara antes - alusão eufemística a uma fase hospitalária de seis meses. No dia 10 de dezembro, o Instituto Goethe - Paris organizou um evento em honra de Nelly Sachs, que incluiu uma leitura de seus poemas, realizada por Celan (CELAN / SACHS 91). Não se percebe um indício de inveja ou ressentimento. No dia 8 de dezembro, o casal havia enviado ainda uma carta de saudação com o poema "Schlafbrocken, Keile" e, relacionado a este, uma gravura de Gisèle Lestrange-Celan. Podemos supor que o poeta considerava a distinção da sua amiga justa e merecida.

Como já foi dito antes, a Comissão tinha a intenção de destacar a literatura de um judaísmo sobrevivente após o Holocausto, dividindo o prêmio entre dois representantes da cultura judaica mundial. No seu discurso, Anders Österling disse que os dois escritores

seriam reunidos, apesar dos idiomas diferentes, por um parentesco intelectual, complementando-se, quase, mutuamente num empenho 
magnífico, de destacar o patrimônio cultural do povo judeu em forma poética de uma fonte comum de inspiração que se revelou em ambos como uma força viva. (apud EsPMARK 1988: 248)

Por um lado, o romancista Shmuel Agnon que vivia na Palestina / em Israel desde a primeira década do século XX, e continuava, em hebraico, a grande tradição narrativa dos asquenaze da Europa Oriental, mas cujo trabalho não tematiza o holocausto. A outra metade da distinção devia, por conseguinte, dirigir-se a uma obra na qual o Holocausto ocupava um lugar central e visível. A partir desta perspectiva, a poesia de Nelly Sachs estava mais habilitada, dado que a obra de Celan, apesar da emblemática "Todesfuge" e de "Engführung", foi considerada mais hermética e, talvez, menos "consolativa". Já Walter Berendsohn havia destacado a qualidade transcendente dos poemas de Nelly Sachs como "lamentando, acusando e transfigurando". ${ }^{26} \mathrm{O}$ elemento reconciliador dos textos foi agradecido e salientado particularmente pelos políticos alemães, que cobriram a autora com prêmios desde o fim dos anos 50 (Sparr 1998; OelKers 1991: 227 s.) A Comissão sueca não compartilhava os motivos dos alemães culpados, mas, mesmo assim, podemos presumir que a política do Prêmio Nobel perseguia uma estratégia mais diplomática e apaziguadora em vez de insistir no incontornável do horror.

Nelly Sachs, naquele momento, foi considerada a "poeta do destino judeu” (BAHR 1980: 12, 18), a última representante de uma literatura judia em língua alemã. ${ }^{27}$ Pode-se calcular também que as denúncias de plágio levantadas contra Paul Celan pela viúva de Ivan Goll houvessem deixado uma mancha na imagem do poeta e que Nelly Sachs era, vivendo na Suécia havia 26 anos, mais conhecida pela maioria dos membros da Comissão. Não é improvável que, ademais, a simetria geracional tenha influenciado a

26 "Klagend, anklagend und verklärend"; carta a Sachs de maio 1946. Apud OELKERS 1991: 222.

27 „Zum anderen wurde ihr die offizielle Anerkennung zuteil, weil ihr Werk ,das einzige große dichterische Zeugnis des jüdischen Schicksals unter nationalsozialistischer Herrschaft (sei), das in deutscher Sprache entstanden' sei." (FISCHER 1986: 252, citando Otto Knörrich) 
decisão: enquanto Celan tinha quase 30 anos de idade a menos, Sachs nasceu somente três anos depois de Shmuel Agnon e os dois faleceram no mesmo ano: 1970. Tanto Sachs quanto Agnon já tinham publicado praticamente sua obra inteira, fato comum em muitos premiados pelo júri de Estocolmo. Que o mesmo valeria para a obra de Paul Celan, não podia ser previsto por ninguém em 1966: O poeta suicidou-se no rio Sena ainda poucos meses antes da morte de Nelly, sua "irmã mais velha". Vida e obra dos dois estão sob o signo do sofrimento de ter sobrevivido e a necessidade, menos de expressar a angústia do que de emprestar a voz aos afogados. 


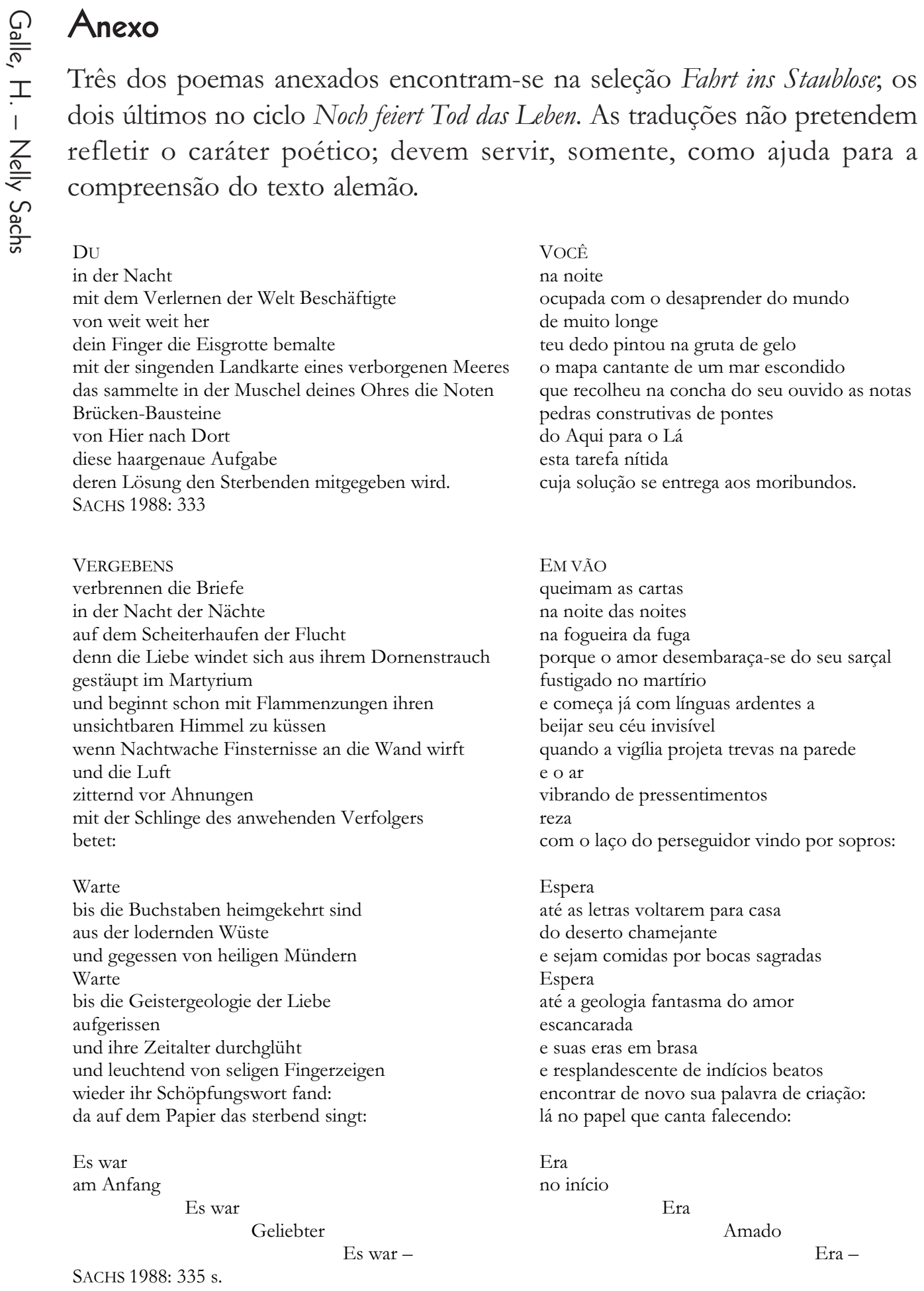


IN DIESEM AMETHYST

sind die Zeitalter der Nacht gelagert und eine frühere Lichtintelligenz zündete die Schwermut an die war noch flüssig und weinte

Immer noch glänzt dein Sterben hartes Veilchen

SACHS 1988: 342

ABER UNTER DEM BLÄTTERDACH vollkommener Vereinsamung die nur für sich alleine stirbt wo jeder fremde Blick verscheidet abstreifend alle Begegnungen auch die der Liebe

bist du

mit vier Windgesichtern in die Fremde schauend König über die Gefilde der Unberührbarkeit eindeutig wie das Gebiß der Toten

das übrig blieb im Staubzerfall

und nur zum Kauen war gesetzt

in seinem Reich

das unterging -

SACHS 1988: 362

\section{SIE TANZT -}

aber mit einem schweren Gewicht -

Warum tanzt sie mit einem schweren Gewicht?

Sie will untröstlich sein -

Ächzend zieht sie ihren Geliebten am Gelock des Weltmeeres aus der Tiefe Atem der Unruhe bläst

auf das rettende Gebälk ihrer Arme

Ein leidender Fisch zappelt sprachlos

an ihrer Liebe -

Aber plötzlich

am Genick

Schlaf beugt sie hinüber -

Freigelassene

sind Leben -

sind Tod -

SACHS 1988: 367
NESTA AMETISTA

os séculos da noite estão armazenados e uma primordial inteligência de luz acendeu a melancolia

que ainda estava fluida

e chorava

Ainda tua morte brilha

violeta duro

MAS POR BAIXO DO FOLHADO

da solidão perfeita

que morre somente para si sozinha

onde cada olhada estrangeira falece

despindo todos encontros

também aqueles de amor

você é

olhando para o forasteiro com quatro caras de vento rei sobre os campos da intangibilidade inequívoco como a dentadura dos mortos

que remanesceu no apodrecimento

e foi colocada só para mastigar

no seu reino

que pereceu -

ELA DANCCA -

mas com uma carga pesada

Porque dança com uma carga pesada?

Ela quer ser inconsolável -

Gemendo ela tira seu namorado

da profundeza no cacho do mar mundial

O hálito da inquietude sopra

no vigamento salvador dos seus braços

Um peixe sofrido estrebucha mudo

no seu amor -

De repente todavia

na nuca

o sono a inclina para o outro lado -

Libertados

são vida -

são morte - 


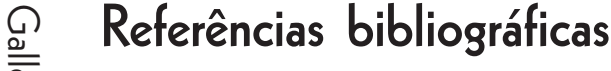

I Celan, Paul / Sachs, Nelly. Briefwechsel. Hg. v. Barbara Wiedemann. Frankfurt a.M. 1993.

Celan, Paul. Die Niemandsrose. Vorstufen - Textgenese - Endfassung. Ed. Jürgen Werheimer. (Tübinger Ausgabe) Frankfurt a.M., Suhrkamp 1996.

Celan, Paul. Der Meridian. Endfassung. Vorstufen. Materialien. Tübinger Ausgabe. Eds. Böschenstein, Bernhard / Schmoll, Heino. Frankfurt a. M., Suhrkamp 1999.

Cellan, Paul. Die Gedichte. Kommentierte Gesamtausgabe. Ed. Barbara Wiedemann Frankfurt a. M., Suhrkamp 2005.

SACHS, Nelly. Fahrt ins Staublose. Gedichte. Frankfurt a.M., Suhrkamp 1988.

SACHS, Nelly. Das Buch der Nelly Sachs. Ed. Bengt HoLMQvist. Frankfurt a.M., Suhrkamp 1977.

BaCH, Inka / Galle, Helmut. Deutsche Psalmendichtung vom 16. bis zum 20. Jahrbundert. Untersuchungen zu einer lyrischen Gattung. Berlin / New York: de Gruyter 1989.

BAHr, Ehrhard. Nelly Sachs. (Autorenbücher 16) München, Beck 1980.

BARNER, Wilfried u.a. Geschichte der deutschen Literatur von 1945 bis zur Gegenwart. München, Beck 1994.

Bolte, Dorothea. „Nelly Sachs”. In: KILly, Walter (Ed.): Literaturlexikon. Bd. 10. 103 s.

Brauneck, Manfred. „Nelly Sachs. Eli. Ein Mysterienspiel vom Leiden Israels.” In: Kindlers neues Literatur-Lexikon. (CD-ROM) München, Net World Vision 2000.

Dinesen, Ruth. Nelly Sachs. Eine Biographie. Trad. Gerecke, Gabriele. Frankfurt a. M., Suhrkamp 1994. (Nelly Sachs. En biografi. 1991)

Dischner, Gisela. „Zu den Gedichten der Nelly Sachs.” In: HolmQvist, Bengt (Ed.). Das Buch der Nelly Sachs. Frankfurt a. M., Suhrkamp 1977. 309-354.

Emmerich, Wolfgang. Paul Celan. Reinbek, Rowohlt 1999. 
EnZensberger, Hans Magnus. „Über die Gedichte der Nelly Sachs.” In: HolmQvist, Bengt (Ed.). Das Buch der Nelly Sachs. Frankfurt a.M., Suhrkamp 1977. 355-362.

Enzensberger, Hans Magnus. „Die Steine der Freiheit.” (1959) In: Kiedaisch, Petra (Ed.): Lyrik nach Auschwitz? Adorno und die Dichter. Stuttgart, Reclam 1995. 73-76.

Espmark, Kjell. Der Nobelpreis für Literatur. Prinzipien und Bewertungen binter den Entscheidungen. Trad. Paul, Fritz / Volz, Ruprecht. Göttingen, Vandenhoeck \& Ruprecht 1988. (Det litterära Nobelpriset. Principer och värderingar bakom besluten. 1986)

FISCHER, Ludwig. Literatur der Bundesrepublik Deutschland bis 1967. (Hansers Sozialgeschichte der deutschen Literatur vom 16. Jahrhundert bis zur Gegenwart. Bd. 10) München, Hanser 1986.

Felstiner, John. Paul Celan. Eine Biographie. München, Beck 1997.

Fritsch-Vivié, Gabriele. Nelly Sachs. Reinbek, Rowohlt 1993.

Grafe, Arne. „Der Tod war mein Lehrmeister”. Begegnung mit Nelly Sachs - Ein Gespräch mit Gisela DisCHNER. 2005. www.philosophia-online.de/ mafo/ heft2005-3/Grafe_Dischner.pdf Acesso no dia 1 de junho 2006.

Hörster, Maria A. „'In der Flucht': a escritora do exílio Nelly Sachs. Elementos para o estudo da sua recepção em Portugal." www.institutocamoes.pt/CVC/bvc/artigos/ mahorster.pdf Acesso no dia 1 de junho 2006.

Inauen, Yasmine. "Verwandelter Körper, verwandeltes Ich. Tanzgedichte von Else Lasker-Schüler, Gertrud Kolmar, Nelly Sachs und Christine Lavant." In: ArNold, Heinz Ludwig (Ed.). Lyrik des 20. Jahrhunderts. Vol. text + kritik XI / 99. München, Edition text + kritik, 1999. 213-230.

KORTE, Hermann. „Der Holocaust in der Lyrik nach 1945.” In: Literatur und Holocaust. Text + Kritik H. 144, 1999. 25-47.

MüLLER, Gerd. Die Literatur der Bundesrepublik und der deutschsprachigen Schweiz. In: ŽMEGAÈ, Viktor (Ed.): Geschichte der deutschen Literatur vom 18. Jahrbundert bis zur Gegenwart. (1979-1984) Digitale Bibliothek Bd. 24, Berlin 1999. Bd. III. 385-548. 
๑ Oelker, Petra. „Und doch, am Ende steht wieder das Licht, wenn auch noch so fern.". In: KerNer, Charlotte (Ed.): Nicht nur Madame Curie ...

I Frauen, die den Nobelpreis bekamen. Weinheim / Basel, Beltz 1991. 208-232.

Z Peterson, Joan. “'Some Gold across the Water': Paul Celan and Nelly Sachs." $\stackrel{\curvearrowright}{\rightleftharpoons} \quad$ In: Holocaust and Genocide Studies 14.2, fall (2000): 197-214.

气े SCHNELL, Ralf. Geschichte der deutschsprachigen Literatur seit 1945. Stuttgart / Weimar, Metzler 1993.

Sparr, Thomas. "Zeit der Todesfuge. Rezeption der Lyrik von Nelly Sachs und Paul Celan.” In: Braese, Stephan, Gehle, Holger, Kiesel, Doron, LoEWy, Hanno (Ed.): Deutsche Nachkriegsliteratur und der Holocaust. Frankfurt, Campus 1998. 43-52.

StEINER, George. "The Scandal of the Nobel Prize." New York Times Review of Books 30/09 1984. 